\title{
Microencapsulation of Bifidobacterium animalis subsp. lactis BB-12 with mannitol
}

\author{
Agnes Kai Lin Yong ${ }^{a}$, Ka Wai Lai ${ }^{a}$, Hasanah Mohamad Ghazali ${ }^{\mathrm{b}}$, Lee Sin Chang ${ }^{\mathrm{b}, \mathrm{c}}$, Liew Phing Pui ${ }^{\text {** }}$ \\ ${ }^{a}$ Department of Food Science with Nutrition, Faculty of Applied Sciences, UCSI University, No. 1, Jalan Menara Gading, UCSI Heights, \\ 56000 Cheras, Kuala Lumpur, Malaysia \\ ${ }^{b}$ Department of Food Science, Faculty of Food Science and Technology, Universiti Putra Malaysia, 43400 UPM Serdang \\ Selangor Darul Ehsan, Malaysia \\ 'Department of Food Sciences, Faculty of Science and Technology, Universiti Kebangsaan Malaysia, 43600 Bangi, Selangor, Malaysia
}

Received 23rd October 2019 / Accepted 14th February 2020

\begin{abstract}
Bifidobacterium animalis subsp. lactis BB-12 (BB-12) was microencapsulated using co-extrusion technology with chitosan coating and the incorporation of mannitol as prebiotic. Optimization of coating material chitosan concentration $(0-0.5 \% \mathrm{w} / \mathrm{v})$ and mannitol concentration $(0-5 \% \mathrm{w} / \mathrm{v})$ as prebiotic were performed to determine the formulation that produces beads with desired properties. The microencapsulation efficiency (MEE) of free and microencapsulated BB-12 (with and without mannitol) were determined. All forms of BB-12 further subjected to sequential digestion in simulated gastric juice (SGJ, pH 2.0) for 2 hours and simulated intestinal juice (SIJ, pH 7.5) for 3 hours. The results indicated that $0.4 \%(\mathrm{w} / \mathrm{v})$ of chitosan coating and $3 \%(\mathrm{w} / \mathrm{v})$ of mannitol were the optimum concentrations to produce microencapsulated BB-12 with the highest MEE of $89.15 \%$ and the average bead size of $805 \mu \mathrm{m}$. The BB-12 beads produced through co-extrusion were spherical with a smooth surface. Throughout the five hours sequential gastrointestinal digestion, both microencapsulated BB-12 with and without mannitol were able to maintain their viable cell count at least $10^{6} \mathrm{CFU} / \mathrm{g}$ at the end of the incubation. The presence of prebiotic mannitol showed a significant protective effect on the microencapsulated BB-12 during gastrointestinal transit.
\end{abstract}

Keywords: Microencapsulation, probiotic, co-extrusion, mannitol, chitosan, Bifidobacterium

\section{INTRODUCTION}

Probiotics are living microorganisms that may contribute health benefits to the human body when sufficient level is found in the digestive tract (Shori, 2017). It is commonly incorporated into dairy-based food products and beverages. Probiotics can provide several beneficial effects to the human body, which can minimize the risk of intestinal infections, irritable bowel syndrome, as well as inflammatory bowel diseases. Besides that, it also effective in the improvement in the digestibility of food products, controlling the cholesterol level in the blood, and preventing atopic allergies (Nualkaekul and Charalampopoulos, 2011; Kechagia et al., 2013). However, a substantial amount of live probiotic bacteria is needed to ensure that an adequate number of probiotic bacteria can reach the large intestine and exert health benefits to the human body (Lai et al., 2020). There is a recommendation stating that the probiotic bacteria should within

*Author for correspondence: Liew Phing Pui, Department of Food Science with Nutrition, Faculty of Applied Sciences, UCSI University, No. 1, Jalan Menara Gading, UCSI Heights, 56000 Cheras, Kuala Lumpur, Malaysia. Email - puilp@ucsiuniversity.edu.my 
the range of $10^{8}-10^{9}$ colony-forming unit per gram $(\mathrm{CFU} / \mathrm{g})$ before consumption to ensure a minimum level of $10^{6}-10^{7} \mathrm{CFU} / \mathrm{g}$ could reach the colon and provide health benefits to human (Kechagia et al., 2013; Shori, 2017).

Bifidobacterium animalis subsp. lactis BB-12 (BB12) has been used as probiotic and is regarded as generally safe strain (Garrigues et al., 2010; Schwendicke et al., 2014). It does not possess unfavorable taste, mouthfeel, and appearance when incorporated into food for consumption (Jungersen et al., 2014). Numerous benefits of BB12 have been documented in several independent clinical trials, which can help in promoting gastrointestinal health, improving glucose tolerance during pregnancy, and lowering the bad cholesterol in patients with type 2 diabetes (Garrigues et al., 2010).

However, the survivability of BB-12 can be easily affected by $\mathrm{pH}$, oxygen, and temperature (Tripathi and Giri, 2014). In other words, the viability of BB-12 will be decreased when exposed to extremely low $\mathrm{pH}$ and high temperature. Since the beneficial effect conferred by probiotic is dependent on its viability and physiological activity in intestines, BB-12 needs to survive well in the exposure of gastric acid and bile in the gastrointestinal tract. Microencapsulation protects the probiotics against harsh conditions and helps to preserve the probiotic survivability (Bernucci et al., 2017).

Prebiotics are defined as the non-digestible dietary components that are beneficial in stimulating the growth of probiotics (Pandey et al., 2015). Ng et al. (2019) encapsulated Lactobacillus plantarum $299 \mathrm{v}$ with oligofructose as the prebiotic. The microencapsulation with FOS improved Lp299v's viability during storage in low $\mathrm{pH}$ fruit juices compared to those without FOS. On the other hand, Siang et al. (2019) incorporated isomalto-oligosaccharide as prebiotic, together with microencapsulated Lactobacillus rhamnosus GG.

By fixing sodium alginate at $1.5 \%(\mathrm{w} / \mathrm{v})$ as a primary coating material, the purpose of this study is to optimize the microencapsulation of Bifidobacterium animalis subsp. lactis BB-12 by using different concentrations of chitosan (coating material) and mannitol. Viability of free and microencapsulated BB-12 (with and without mannitol) during sequential simulated gastrointestinal digestion were carried out.

\section{MATERIALS AND METHODS}

\section{Materials and chemicals}

Bifidobacterium animalis subsp. lactis BB-12 (BB-12) was purchased from BIO-LIFE, Malaysia. Acetic acid glacial and disodium hydrogen phosphate $\left(\mathrm{Na}_{2} \mathrm{HPO}_{4}\right)$ were purchased from Friedemann Schmidt, Australia. Anhydrous calcium chloride $\left(\mathrm{CaCl}_{2}\right)$, chitosan, sodium alginate, and Tween 80 were obtained from R\&M Chemicals, United Kingdom. Bile salt, D-mannitol, pepsin, and sodium chloride $(\mathrm{NaCl})$ were obtained from Chemsoln, India. Both Bifidus Selective Medium (BSM) agar and broth powder were purchased from HiMedia, India. Hydrochloric acid $(\mathrm{HCl})$, sodium hydroxide $(\mathrm{NaOH})$, and sodium citrate were purchased from Merck KGaA, Germany, while potassium dihydrogen phosphate $\left(\mathrm{KH}_{2} \mathrm{PO}_{4}\right)$ was obtained from Bendosen, Germany.

\section{Optimization of chitosan}

Chitosan solution was prepared freshly by dissolving chitosan powder into $900 \mathrm{~mL}$ of distilled water, where $10 \mathrm{~mL}$ of glacial acetic acid was added with the aid of hotplate magnetic stirrer (HTS-1003, LMS, Japan). $\mathrm{CaCl}_{2}(20 \mathrm{~g})$ and $1 \mathrm{~mL}$ of Tween 80 were dissolved into chitosan solution, and $\mathrm{NaOH}$ solution was used to adjust the chitosan solution to $\mathrm{pH}$ 5. The solution was topped up until $1 \mathrm{~L}$ using distilled water and was pasteurized at $72^{\circ} \mathrm{C}$ for about 30 seconds (Chew et al., 2015). The optimization of chitosan was done using different concentrations of chitosan solution $[0.1 \%, 0.2 \%, 0.3 \%, 0.4 \%$ and $0.5 \%$ $(\mathrm{w} / \mathrm{v})]$ in the microencapsulation process. The concentration of alginate was fixed at $1.5 \%(\mathrm{w} / \mathrm{v})$ by dissolving $15 \mathrm{~g}$ sodium alginate powder into 1 $\mathrm{L}$ distilled water with the aid of magnetic stirrer. The solution was autoclaved at $121^{\circ} \mathrm{C}$ for 15 minutes and stored in the chiller at $4^{\circ} \mathrm{C}$ overnight. The optimal chitosan concentration was then being selected based on bead size and microencapsulation efficiency. 


\section{Optimization of mannitol}

Mannitol solution was prepared by adding mannitol powder into $100 \mathrm{~mL}$ of distilled water and sterilized under $121^{\circ} \mathrm{C}$ for 15 minutes in an autoclave machine (HV-110, Hirayama, Japan). The microencapsulation process was repeated by using different mannitol concentration of $1.0 \%$ $5.0 \%(\mathrm{w} / \mathrm{v})$, with chitosan concentration fixed at $0.4 \% \quad(\mathrm{w} / \mathrm{v})$. The viable cell count and microencapsulation efficiency (MEE) were calculated based on equation [1] and [2] below (Yee et al., 2019).

$$
\text { Viable cell count }(\mathrm{CFU} / \mathrm{mL})=\frac{\text { Average number of colonies }}{\text { Dilution factor } \times \text { volume plated }}
$$

Microencapsulation efficiency, $\operatorname{MEE}(\%)=\left(\log \mathrm{N} / \log \mathrm{N}_{\mathrm{i}}\right)$ x 100

where $\mathrm{N}=$ number of microencapsulated probiotics released from beads and $\mathrm{N}_{\mathrm{i}}=$ number of probiotics in the initial microbial suspension.

\section{Microencapsulation of $\mathrm{BB}-12$ using co- extrusion technique}

Microencapsulation of BB-12 was carried out using Büchi Encapsulator B-390 (Büchi, Switzerland) through the co-extrusion method with modifications (Chew et al., 2015). All the glassware and equipment were under sterilizing conditions by autoclaving at $121^{\circ} \mathrm{C}$ for 15 minutes before microencapsulation. The core fluid (BB-12 with or without mannitol) and shell fluid (sodium alginate solution) were connected to the concentric nozzle of the encapsulator. During the microencapsulation process, the core fluid and shell fluid were pumped simultaneously through the inner nozzle $(200 \mu \mathrm{m})$ and outer nozzle $(300$ $\mu \mathrm{m})$, respectively, using air pressure of 600 mbar to produce a core shell-fluid stream. The vibration frequency of the nozzle was applied at $300 \mathrm{~Hz}$, followed by an amplitude of 3 and a voltage of 1.5 $\mathrm{kV}$.

\section{Morphology and size of bead}

A total of 20 randomly selected BB-12 beads were determined in their morphology and the average size in diameter, using a Nikon YS100 optical microscope (Nikon Corporation, Japan) with x100 magnification. The size of the BB-12 beads was measured with the aid of the stage micrometer, and the measurement was then recorded (Chia et al., 2015).

\section{Survival of Bifidobacterium BB-12 under sequential simulated gastrointestinal conditions}

The simulated gastric juice (SGJ) and simulated intestinal juice (SIJ) were prepared according to the method by Chia et al. (2015). SGJ was prepared by adding $3.5 \mathrm{~mL}$ of $0.1 \mathrm{M} \mathrm{HCl}$ and $1 \mathrm{~g}$ of $\mathrm{NaCl}$ into $500 \mathrm{~mL}$ of distilled water. The $\mathrm{pH}$ was then adjusted to $\mathrm{pH} 2.0$ with $\mathrm{HCl}$ using $\mathrm{pH}$ meter (Eutech Instrument, USA), followed by autoclaving at $121^{\circ} \mathrm{C}$ for 15 minutes and cool until room temperature before adding $1.6 \mathrm{~g}$ of pepsin. On the other hand, SIJ was conducted by mixing $3.4 \mathrm{~g}$ of $\mathrm{KH}_{2} \mathrm{PO}_{4}$ and $0.1 \mathrm{M} \mathrm{NaOH}$ with the amount of $95 \mathrm{~mL}$, and further added with $125 \mathrm{~mL}$ distilled water. The mixture was mixed well with the aid of magnetic stirrer, and the $\mathrm{pH}$ of the mixture was adjusted to $\mathrm{pH} 7.5$ with $\mathrm{NaOH}$. The mixture was then topped up to $500 \mathrm{~mL}$ using distilled water, followed by sterilizing at $121^{\circ} \mathrm{C}$ for 15 minutes and cooled to room temperature before adding $3.0 \mathrm{~g}$ of bile salt.

Sequential digestion was performed according to the protocol from Chia et al. (2015) with slight modification. Survivability of BB-12 was evaluated under simulated gastrointestinal condition, which consists of $1 \mathrm{~g}$ of beads (with or without mannitol) or $1 \mathrm{~mL}$ of BB-12 free cells were transferred into $9 \mathrm{~mL}$ of sterile SGJ. The mixture was then mixed gently and was incubated at $37^{\circ} \mathrm{C}$ for 0 hours, 1 hour, and 2 hours, respectively, using a water bath (Memmert, Germany) with constant agitation at $150 \mathrm{rpm}$. The BB-12 free cell or BB-12 beads at 0-hour function as control. For each hour, the beads or free cells were collected by filtration using nylon sieve and centrifugation under $3510 \times \mathrm{g}$ for 10 minutes at $4^{\circ} \mathrm{C}$ (Centrifuge $5804 \mathrm{R}$, Eppendorf, Germany), respectively to determine the viability of BB-12. Beads or free cells after 2 hours of incubation in SGJ were then transferred to sterile SIJ, followed by further incubation at $37^{\circ} \mathrm{C}$ for 3 hours. 
Similarly, at each hour, the beads or free cells in SIJ were collected by filtration and centrifugation under $3510 \times \mathrm{g}$ for 10 minutes at $4^{\circ} \mathrm{C}$, respectively. At each interval of incubations, the beads were filtered and rinsed with sterile phosphate buffer saline (PBS, containing $9 \mathrm{~g} / \mathrm{L}$ of $\mathrm{NaCl}, 0.144 \mathrm{~g} / \mathrm{L}$ of $\mathrm{KH}_{2} \mathrm{PO}_{4}$ and $0.795 \mathrm{~g} / \mathrm{L}$ of $\mathrm{Na}_{2} \mathrm{HPO}_{4}$ ) to remove the remaining SGJ or SIJ solution on the beads. The rinsed beads $(1 \mathrm{~g})$ were then being transferred to $9 \mathrm{~mL}$ of sodium citrate in a stomacher bag (Copens Scientific, Malaysia) underwent speed setting to break the beads by using a stomacher $\left(\right.$ BagMixer $^{\circledR} \quad 400 \mathrm{~W}$, Interscience, France). However, for free cells, the cell pellet collected from centrifugation was rinsed twice with PBS. The cell pellet was then resuspended in $9 \mathrm{~mL}$ of PBS for cell enumeration.

The mixture (homogenized beads in $9 \mathrm{~mL}$ of sodium citrate or cell pellet dissolved in $9 \mathrm{~mL}$ of PBS) was serially diluted using PBS. Aliquot of 0.1 $\mathrm{mL}$ of the mixture was pipetted onto the Petri dish, followed by pouring the $50^{\circ} \mathrm{C}$ molten $\mathrm{BSM}$ agar onto the agar plate and swirled gently. After the BSM agar had been solidified, the agar plate was sealed properly using parafilm and incubated at $37^{\circ} \mathrm{C}$ for 48 hours in an upside-down position. The viability of all BB-12 was expressed as log $\mathrm{CFU} / \mathrm{mL}$ using equation [1], while survivability was calculated using equation [3] (Yee et al., 2019).

Survivability $(\%)=\left(\log \mathrm{N}_{\mathrm{t}} / \log \mathrm{N}_{0}\right) \times 100$

Where $\mathrm{N}_{\mathrm{t}}=$ number of viable cells in the free cell after incubation in SGJ or SIJ condition

and $\mathrm{N}_{0}=$ number of viable cells at 0 -hour incubation

\section{Statistical analysis}

All the samples and analyses were conducted in triplicate $(n=3)$. The data were analyzed using MINITAB 17 (Minitab Statistical Software, Minitab Inc., USA), and the results were expressed as mean \pm standard deviation. One-way analysis of variance (ANOVA) and paired $t$-test were performed, where the mean values were compared with Tukey's post hoc test, with $\mathrm{p} \leq$ 0.05 of significant difference.

\section{RESULTS}

\section{Optimization of chitosan concentration}

The optimization process to determine the most suitable concentration of chitosan (coating material) and mannitol (prebiotic) for the microencapsulation of Bifidobacterium animalis subsp. lactis BB-12 (BB-12) was performed. Table 1 shows the microencapsulation efficiency (MEE) and the average bead size of the microencapsulated BB-12 with different concentrations of chitosan. Chitosan with a concentration of $0 \%(\mathrm{w} / \mathrm{v})$ function as control during the optimization process. Table 1 shows that there was no significant effect $(\mathrm{p}>0.05)$ on the MEE of the encapsulated BB-12 with the increase of chitosan concentration $(0.1 \% \mathrm{w} / \mathrm{v}$ to $0.3 \% \mathrm{w} / \mathrm{v})$, while at $0.4 \%(\mathrm{w} / \mathrm{v})$ chitosan, the MEE of the beads was the highest $(89.13 \%)$. With a further increase in chitosan concentration $(0.5 \%$ $\mathrm{w} / \mathrm{v})$, the MEE found to decrease to $86.79 \%$.

The result was in agreement with Shori (2017), who reported that increasing chitosan concentration was able to produce beads with high encapsulation yield. This is because the porosity in alginate bead was reduced as the concentration increased from $0.1 \%$ to $0.4 \%(\mathrm{w} / \mathrm{v})$ (Table 1), which cause alginate bead to have high stability and able to minimize the encapsulated probiotic from leakage (Krasaekoopt et al., 2003, Chávarri et al., 2010). However, the presence of chitosan only improves the microencapsulation of the beads to a certain extent. This indicates that the further increase of chitosan concentration to $0.5 \%(\mathrm{w} / \mathrm{v})$ lowered the efficacy of encapsulation as a higher chitosan concentration could lead to the production of beads with a thicker membrane, which reduced the release rate of encapsulated probiotic (Trabelsi et al., 2013).

Among other chitosan concentrations, the MEE of the BB-12 beads coated with $0.4 \%(\mathrm{w} / \mathrm{v})$ of chitosan was the highest. The result was in agreement with Krasaekoopt et al. (2004), who reported that $0.4 \%(\mathrm{w} / \mathrm{v})$ chitosan gave better protection of probiotic (Lactobacillus acidophilus, Lactobacillus casei and Bifidobacterium bifidum). Therefore, chitosan with a concentration of $0.4 \%$ $(\mathrm{w} / \mathrm{v})$ was selected as the optimal concentration as its MEE was the highest among other beads. On the other hand, the increased in chitosan 
concentration showed no significant effect ( $p>0.05$ ) on the average size of BB-12 beads, with the range of 709.10 to $800.00 \mu \mathrm{m}$ (Table 1). Koo et al. (2001) also reported that the addition of chitosan into alginate microcapsules would not affect the size of the beads. In the present study, the size of BB-12 beads was slightly larger as the chitosan's concentration increased (Table 1). However, the chitosan concentrations have no significant effect $(p>0.05)$ on the size of BB-12 bead based on statistical analysis. A similar result was also reported by Chew et al. (2015) as the size ranges of kenaf seed oil entrapped in alginate-high methoxyl pectin microcapsules coated with different concentrations of chitosan were similar especially in concentrations below $0.4 \%(\mathrm{w} / \mathrm{v})$. The increase of the size of kenaf seed oil microcapsules was more pronounced as the concentration of chitosan was elevated from $0.1 \%$ $(\mathrm{w} / \mathrm{v})$ to $1.0 \%(\mathrm{w} / \mathrm{v})$. This was supported by Wei et al. (2020), whereby the average size of chitosantripolyphosphate beads entrapped with theophylline enhanced from $280 \mathrm{~nm}$ to $415 \mathrm{~nm}$ when the chitosan concentration was doubled up $0.05 \%$ to $0.1 \%(\mathrm{w} / \mathrm{v})$.

Table 1. Microencapsulation efficiency and bead size of encapsulated BB-12 using different concentration of chitosan.

\begin{tabular}{ccc}
\hline Chitosan $(\% \mathbf{w} / \mathbf{v})$ & Microencapsulation efficiency (\%) & Diameter of beads $(\boldsymbol{\mu m})$ \\
\hline 0.0 & $87.17 \pm 0.68^{\mathrm{ab}}$ & $709.10 \pm 66.40^{\mathrm{a}}$ \\
0.1 & $88.12 \pm 0.70^{\mathrm{ab}}$ & $754.50 \pm 93.40^{\mathrm{a}}$ \\
0.2 & $87.60 \pm 1.47 \mathrm{ab}$ & $743.20 \pm 68.30^{\mathrm{a}}$ \\
0.3 & $88.14 \pm 0.60^{\mathrm{ab}}$ & $790.90 \pm 44.60^{\mathrm{a}}$ \\
0.4 & $89.13 \pm 0.64^{\mathrm{b}}$ & $736.40 \pm 97.70^{\mathrm{a}}$ \\
0.5 & $86.79 \pm 0.54^{\mathrm{a}}$ & $800.00 \pm 63.20^{\mathrm{a}}$ \\
\hline
\end{tabular}

a-bMeans \pm standard deviations followed by different superscript letters within the same column are significantly different at $\mathrm{p} \leq 0.05$ according to Tukey's test $(\mathrm{n}=3)$.

\section{Optimization of mannitol concentration}

The effect of different concentrations of mannitol on the MEE and the average size of entrapped BB-12 in chitosan coated-alginate beads are shown in Table 2. The concentration of sodium alginate and chitosan was set at $1.5 \%(\mathrm{w} / \mathrm{v})$ and $0.4 \%(\mathrm{w} / \mathrm{v})$, respectively while the concentration of calcium chloride was fixed at $2.0 \%(\mathrm{w} / \mathrm{v})$. Mannitol with concentration of $0 \%(\mathrm{w} / \mathrm{v})$ was functioned as control. According to Table 2, the MEE of the beads increased when the mannitol concentration was increased from $1.0 \%$ to $3.0 \%$ $(\mathrm{w} / \mathrm{v})$. However, when the concentration of mannitol increased from $3.0 \%(\mathrm{w} / \mathrm{v})$ to $4.0 \%$ $(\mathrm{w} / \mathrm{v})$, the MEE of the BB-12 beads coated with chitosan was decreased. The result showed no significant differences $(p>0.05)$ in MEE when the mannitol concentration increased from $4.0 \%$ $(\mathrm{w} / \mathrm{v})$ to $5.0 \%(\mathrm{w} / \mathrm{v})$.

Table 2 also shows that the MEE of beads without mannitol was the lowest $(75.54 \%)$ as compared to those beads with the presence of mannitol. The result was supported by $\mathrm{Ng}$ et al. (2019), who stated that the addition of prebiotic oligofructose improved the encapsulation yield of Lactobacillus plantarum 299v coated with chitosan.
The encapsulation efficiency of the entrapped $L$. plantarum $299 \mathrm{v}$ was enhanced to $93.9 \%$. Oligofructose serves as the food source for probiotics, and thus improve its survivability during adverse conditions. Therefore, encapsulated probiotic bacteria with the addition of prebiotic survived better when compared to the encapsulated probiotic without the prebiotic (Yee et al., 2019).

The MEE of the BB-12 beads incorporated with mannitol decreased in the concentration beyond $3 \%(\mathrm{w} / \mathrm{v})$, as shown in Table 2 . This is because increasing prebiotic concentration might cause a higher mass in the beads and thus, lowering the entrapped probiotic bacteria in the beads ( $\mathrm{Ng}$ et al., 2019). The MEE of the bead using $3.0 \%(\mathrm{w} / \mathrm{v})$ of mannitol was the highest (94.15\%, Table 2) as compared to other mannitol concentrations. The result was similar to the study by Martín et al. (2015), who also performed the microencapsulation of Lactobacillus lactis using $3.0 \%(\mathrm{w} / \mathrm{v})$ of mannitol. Hence, mannitol with a concentration of $3.0 \%(\mathrm{w} / \mathrm{v})$ was selected as the optimal concentration for the study, as it produces the beads with the highest MEE. 
Furthermore, Table 2 also shows that there were no significant differences $(\mathrm{p}>0.05)$ on the diameter of beads regardless of the mannitol concentrations. Krasarkoopt and Watcharapoka
(2014) reported that the type and concentrations of prebiotics did not influence the size of encapsulated probiotics.

Table 2. Effect of different concentration of mannitol on the microencapsulation efficiency and bead size of encapsulated BB-12 coated with chitosan.

\begin{tabular}{ccc}
\hline Mannitol $(\% \mathbf{w} / \mathbf{v})$ & Microencapsulation efficiency $(\%)$ & Diameter of beads $(\boldsymbol{\mu m})$ \\
\hline 0 & $75.54 \pm 2.44^{\mathrm{a}}$ & $777.50 \pm 65.80^{\mathrm{a}}$ \\
2 & $76.46 \pm 1.19^{\mathrm{a}}$ & $802.50 \pm 55.00^{\mathrm{a}}$ \\
3 & $84.98 \pm 2.01^{\mathrm{b}}$ & $787.50 \pm 70.50^{\mathrm{a}}$ \\
4 & $94.15 \pm 1.71^{\mathrm{c}}$ & $785.00 \pm 58.70^{\mathrm{a}}$ \\
5 & $88.83 \pm 1.40^{\mathrm{b}}$ & $807.50 \pm 69.30^{\mathrm{a}}$ \\
\hline
\end{tabular}

a-cMeans \pm standard deviations followed by different superscript letters within the same column are significantly different at $\mathrm{p} \leq 0.05$ according to Tukey's test $(\mathrm{n}=3)$.

\section{Morphology and size of beads}

Figure 1 shows the BB-12 bead produced through co-extrusion using an optical microscope with the aid of the stage micrometer. Based on Figure 1, the bead was white in color, spherical in shape with a smooth surface, and surrounded by a thin layer of the membrane. There were some of the microcapsules produced with an irregular tailed shape, and the diameter of the microcapsules produced was big as well. However, throughout the microencapsulation process, most of the beads produced were spherical and uniform in shape, which is desirable and as expected in coextrusion (Siang et al., 2019; Yee et al., 2019). The beads protect and maintain the viability and the survivability of the encapsulated cells.

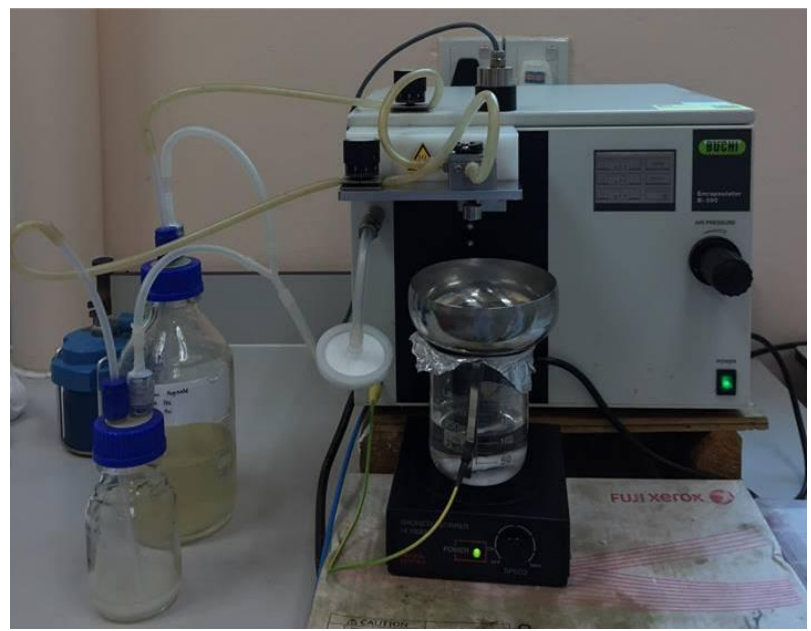

Figure 1. Büchi Encapsulator B-390.

The tailed shape and the deformation of the bead size could be due to several factors, including the size of nozzles used during co- extrusion, the equipment parameters such as vibration frequency, flow rate, and electrode tension, as well as the viscosity of sodium alginate, chitosan and calcium chloride (Dolçà et al., 2015). The concentration of sodium alginate strongly affects the size of the beads. Therefore, it is essential to prepare sodium alginate solution with appropriate concentration to minimize the production of deformed beads or tailed shape beads, as spherical beads can enhance the survivability of the encapsulated cells (Chan et al., 2009; Krasaekoopt, 2013). According to Piazza and Roversi (2011), sodium alginate with a concentration between $1 \%(\mathrm{w} / \mathrm{v})$ and $2 \%(\mathrm{w} / \mathrm{v})$ was effective in producing spherical and smooth bead size. The microencapsulation efficiency of the encapsulated BB-12 with and without mannitol is shown in Table 3.

From Table 3, it can be observed that the diameter of the encapsulated BB-12 with and without mannitol was $758.50 \pm 55.00 \mu \mathrm{m}$ and $805.00 \pm 58.30 \mu \mathrm{m}$, respectively. Piazza and Roversi (2011) also obtained the microcapsules within the size ranged between $700 \mu \mathrm{m}$ and 800 $\mu \mathrm{m}$ using the co-extrusion technique. However, the result was not in agreement with Silva et al. (2016), who utilized the co-extrusion method and produced microcapsules in which the diameter has exceeded $1000 \mu \mathrm{m}$. The larger bead sizes are influenced by different factors, which include the distance between nozzles and the viscosity of sodium alginate used in the microencapsulation process (Solanki et al., 2013). Apart from that, the microencapsulation technique used was also one of the factors that cause the difference in bead 
size. According to Dolçà et al. (2015), beads produced by co-extrusion would have a bigger bead size due to the presence of water in the microcapsules.

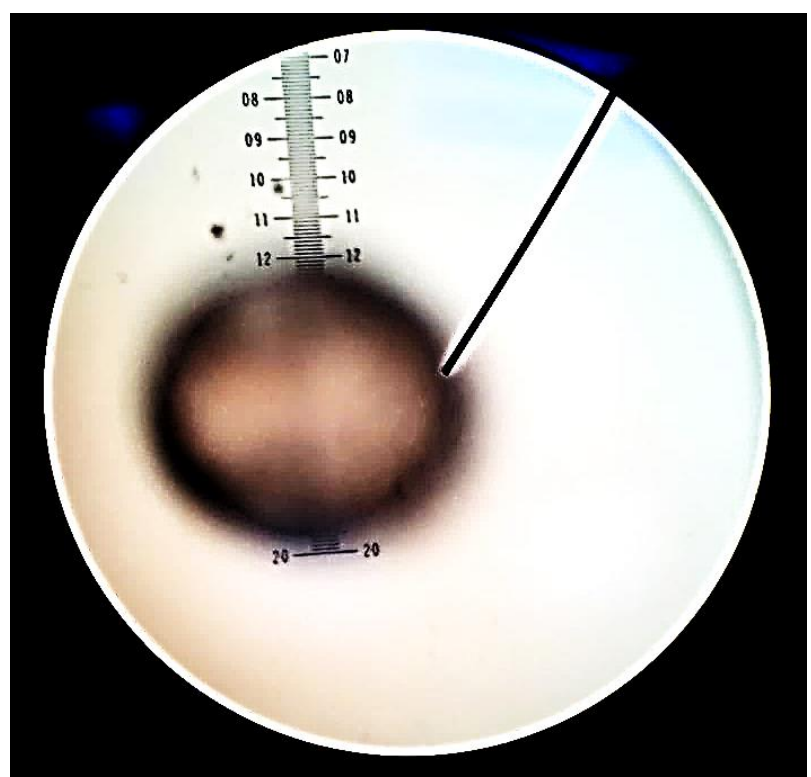

Figure 2. Shape and size of the microcapsules measured with the aid of stage micrometer.

The incorporation of mannitol into encapsulated BB-12 showed no significant effect $(\mathrm{p}>0.05)$ on the diameter of the beads, as shown in Table 3. The result was supported by Haghshenas et al. (2015), who stated that the addition of the inulin would not affect the diameter of the microcapsules. Also, the present findings were in agreement with $\mathrm{Ng}$ et al. (2019), who reported that the diameter of L. plantarum $299 \mathrm{v}$ entrapped in chitosan-coated alginate beads was in the range of 736-776 $\mu \mathrm{m}$ with varying concentrations of oligofructose. The reported size range was slightly higher with the present study $(778-807 \mu \mathrm{m})$ is probably due to the selection of larger inner nozzles $(200 \mu \mathrm{m})$ as compared to $150 \mu \mathrm{m}$ by the authors.

Table 3 also demonstrates that the MEE of BB-12 beads with and without mannitol were $77.32 \%$ and $89.15 \%$, respectively. The MEE of the encapsulated BB-12 incorporated with mannitol was higher when compared to those without mannitol. The incorporation of prebiotic mannitol into the microencapsulation of probiotic cells has enhanced the stability of the cell envelops of probiotic bacteria (Das et al., 2014). Succi et al. (2017), also reported that the presence of mannitol improved the growth capabilities of Lactobacillus rhamnosus AT194, Lactobacillus rhamnosus AT195, and Lactobacillus GG. In the work of Jantarathin et al. (2017), the encapsulation of different probiotic bacteria with prebiotic inulin and coated with chitosan were found to improve the survivability of the encapsulated probiotic bacteria under heat processing.

The result showed that $3 \%(\mathrm{w} / \mathrm{v})$ of mannitol had been successfully preserved the viability of BB-12 during the encapsulation process with high MEE. The MEE can be increased when the coating material and the prebiotic were used with appropriate concentration (Shinde et al., 2013).

Table 3. Average bead size in diameter $(\mu \mathrm{m})$ and microencapsulation efficiency $(\%)$ of encapsulated BB12.

\begin{tabular}{ccccc}
\hline Probiotic & Prebiotic & Microencapsulation type & Diameter $(\boldsymbol{\mu m})$ & $\begin{array}{c}\text { Microencapsulation } \\
\text { efficiency }(\%)\end{array}$ \\
\hline BB-12 & - & Calcium-alginate-chitosan & $758.50 \pm 55.00^{\mathrm{a}}$ & $77.32 \pm 0.47^{\mathrm{a}}$ \\
BB-12 & Mannitol & Calcium-alginate-chitosan & $805.00 \pm 58.30^{\mathrm{a}}$ & $89.15 \pm 0.20^{\mathrm{b}}$ \\
\hline
\end{tabular}

a-bMeans \pm standard deviations followed by different superscript letters within the same column are significantly different at $\mathrm{p} \leq 0.05$ using a paired $t$-test $(\mathrm{n}=3)$.

\section{Sequential digestion for free cell and encapsulated BB-12 with and without mannitol}

The viability and survivability of free and encapsulated BB-12 (with and without mannitol) under sequential digestion are shown in Table 4 and Table 5, respectively. Table 4 and Table 5 show that the viability and survivability of all forms of BB-12 (free and encapsulated) decreases after two hours of incubation in the SGJ at $\mathrm{pH} 2$. Probiotic BB-12 was relatively sensitive towards the low $\mathrm{pH}$ of gastric juice. As for free BB-12, the viability decreased by $26.05 \%$ (from 8.29 to 6.13 of average $\log \mathrm{CFU} / \mathrm{mL}$ ) at the end of SGJ incubation (Table 4). On the other hand, Table 4 also shows that the encapsulated BB-12 without and with mannitol experienced a smaller reduction in viability (1.06 and $0.26 \log$ reduction, 
respectively) as compared to free BB-12 throughout SGJ digestion. This shows that the encapsulated BB-12 was able to protect its viability when exposing to a low $\mathrm{pH}$ environment. Similar results were reported by Siang et al. (2019), whereby the viability of encapsulated Lactobacillus rhamnosus GG in poly-L-lysine coated-alginate microbeads with or without prebiotic (isomaltooligosaccharides) was significantly higher than its respective free cell form after SGJ digestion.

The viability of the encapsulated BB-12 with mannitol at the end of SGJ incubation was the highest $\left(>10^{8} \mathrm{CFU} / \mathrm{mL}\right.$, Table 4$)$, with the least reduction $(2.72 \%$, Table 5$)$. This suggests that the addition of mannitol provided a favorable effect on the survival of encapsulated BB-12 in an acidic environment. Shori et al. (2017) also showed that the addition of prebiotic has a positive effect in protecting the encapsulated Lactobacillus plantarum, which leads to higher probiotic viability during gastrointestinal transit. Besides that, the viability of the encapsulated BB-12 with mannitol showed no significant differences $(\mathrm{p}>0.05)$ between the $1^{\text {st }}$ and $2^{\text {nd }}$ hour of SGJ incubation (Table 4$)$. The viability loss of BB-12 (free and encapsulated) was in agreement with Mustafa et al. (2016), who highlighted that the probiotic bacteria experienced loss in viability when exposed to the acidic condition.

According to Table 5, the survivability of the BB-12 free cell was 73.95\% throughout the twohours incubation in SGJ, which was significantly lower than the encapsulated BB-12 with mannitol (97.28\%) and without mannitol (87.33\%). Besides that, the encapsulated BB-12 with mannitol exhibited the highest survival rate as compared to free and encapsulated BB-12 without mannitol (Table 5). This illustrated that the encapsulation of BB-12 with mannitol supports the growth of BB-12 as mannitol served as the food source for the probiotic (Yee et al., 2019).

The data indicates that microencapsulation was useful and effective in protecting probiotic BB-12 at high survival rates. The result obtained was similar to Shori (2017), who reported that the viability of microencapsulated Bifidobacterium lactis and Lactobacillus paracasei were enhanced when compared to the respective free cell throughout 90 minutes of incubation under SGJ at $\mathrm{pH} 2$. Besides that, Chávarri et al. (2010) also pointed out that the survivability of Lactobacillus gasseri and
Bifidobacterium bifidum encapsulated with sodium alginate and chitosan were improved. They also concluded that the viability of both probiotic bacteria was able to maintain at approximately $10^{7}$ $\mathrm{CFU} / \mathrm{mL}$ as compared to the free cell when exposed to the gastric environment for two hours.

After the two hours of incubation in SGJ, the viability and survivability of all forms of BB-12 (free and encapsulated) were tested in SIJ at $\mathrm{pH}$ 7.5 for 3 hours (Table 4 and Table 5, respectively). Table 4 shows that the viability of free BB-12 showed no significant difference $(p>0.05)$ after three hours of incubation under SIJ (from $6.10 \pm$ 0.14 to $5.97 \pm 0.06 \log \mathrm{CFU} / \mathrm{mL}$ ). The viability of BB-12 free cell after five hours incubation was unable to exert its health benefit to the host as the viability was not within the minimum probiotic concentration of $10^{6} \mathrm{CFU} / \mathrm{mL}$. In the work of Chávarri et al. (2010), the amount of viable Lactobacillus gasseri free cell dropped to less than 1 $\log \mathrm{CFU} / \mathrm{mL}$ after exposure in SIJ for two hours.

However, the viability of the free BB-12 was not significantly different $(p>0.05)$ throughout the 3 hours of incubation in SIJ (Table 4). This elucidates that BB-12 was not sensitive to bile; in fact, it exhibits high bile tolerance up to $1 \%$ (Vernazza et al., 2006). This was probably due to the presence of the gene coding for bile salt hydrolase (Jungersen et al., 2014). This enzyme allows the probiotic to cope and survive in the small intestine region with high bile salt concentrations (Ruiz et al., 2013).

Apart from that, the viability of encapsulated BB-12 with and without mannitol dropped from $10^{7} \mathrm{CFU} / \mathrm{mL}$ to 7.02 and $6.96 \log \mathrm{CFU} / \mathrm{mL}$, respectively (Table 4). This demonstrated that the encapsulation process by co-extrusion could preserve the viability of $\mathrm{BB}-12$ above the recommended level of $10^{6} \mathrm{CFU} / \mathrm{mL}$ as compared to the free BB-12 even though the viability of both encapsulated BB-12 decreased during SIJ digestion. This may be probably due to the presence of $\mathrm{pH}$-dependent polyelectrolyte complexes (PECs) on the beads' surface due to the ionic interaction between the positively charged chitosan and negatively charged alginate (Du et al., 2015). These PECs were insoluble in the acidic environment, which prevents the leakage of BB-12 during SGJ digestion.

However, as the beads were exposed to a neutral or alkaline environment, the PECs were 
solubilized, the beads were swelled due to uptake of water, and accelerated the release of BB-12, thus lowering its viability in the beads (Yee et al., 2019). This suggested that the chitosan-coated alginate beads could provide a sustainable or controlled release of BB-12 across the intestinal tract. The swelling of the chitosan coated-alginate beads in neutral $\mathrm{pH}$ is one of the significant factors that govern the controlled release of the entrapped active components in microencapsulation, especially for enteric delivery (Chew et al., 2015). Similar results were reported by Cook et al. (2011) such that the PECs between chitosan and alginate can improve the survival of Bifidobacterium breve during SGJ and prolong its release of upon exposure to SIJ.

Table 5 also shows that the survivability of free BB-12 $(73.57 \%-71.99 \%)$ was not significantly different $(\mathrm{p}>0.05)$ during SIJ digestion. In comparison, the survival rates of the encapsulated BB-12 with and without mannitol had been reduced by $3.13 \%$ and $3.06 \%$, respectively. The survivability of both encapsulated BB-12 was higher than the free cell form at the end of sequential digestion. This indicates that the chitosan coated-alginate beads produced by the co-extrusion technique provided efficient protective effect to entrapped BB-12, which preserve its viability and survivability during adverse conditions in gastrointestinal digestion as compared to a free cell. Incorporation of chitosan into alginate microcapsules can overcome the porosity of alginate beads and protect the microencapsulated probiotic from leakage (Chávarri et al., 2010). Trabelsi et al. (2013) also reported that microencapsulation of Lactobacillus plantarum TN8 using alginate and chitosan has successfully enhanced its viability in the presence of bile salt when compared to the free cells.

Furthermore, the survivability of the encapsulated BB-12 with and without the incorporation of mannitol were $83.64 \%$ and $83.74 \%$, respectively, which was higher than free BB-12. This elucidated that the addition of mannitol as prebiotic did not improve the viability of BB-12 during exposure to SIJ digestion. This was in agreement with $\mathrm{Ng}$ et al. (2019), such that the survivability of encapsulated Lactobacillus plantarum $299 \mathrm{v}$ with and without FOS was not significantly different $(\mathrm{p}>0.05)$ with each other after 4 hours of incubation in SIJ. Also, the freezedried encapsulated Lactobacillus acidophilus La-14 with Hi-maize failed to achieve viability above the minimum recommended level of $10^{6} \mathrm{CFU} / \mathrm{mL}$ after sequential digestion (Etchepare et al., 2016). The microencapsulated BB-12 with and without mannitol were able to preserve the viability and high survival rate after the sequential digestion. Besides that, the encapsulated BB-12 with and without mannitol have met the minimum viable cell concentration of $10^{6}$ to $10^{7} \mathrm{CFU} / \mathrm{mL}$ (Shori, 2017). However, BB-12 free cells failed to fulfill the minimum viable cell concentration requirement as its viability was less than $10^{6}$ $\mathrm{CFU} / \mathrm{mL}$. Therefore, this indicates that the encapsulated probiotic BB-12 with and without mannitol were able to provide health benefits to humans as they can survive against the physiological stressful condition.

Table 4. Viability of BB-12 free cell and microencapsulated BB-12 with and without mannitol under sequential digestion.

\begin{tabular}{ccccc}
\hline \multirow{2}{*}{$\begin{array}{c}\text { Sequential } \\
\text { incubation }\end{array}$} & Time (h) & Free cell & Encapsulated BB-12 & $\begin{array}{c}\text { Encapsulated BB-12 } \\
\text { with mannitol }\end{array}$ \\
\cline { 3 - 5 } & & $8.29 \pm 0.10^{\mathrm{a}}$ & $8.30 \pm 0.06^{\mathrm{a}}$ & $8.36 \pm 0.03^{\mathrm{a}}$ \\
SGJ (pH 2.0) & 1 & $7.56 \pm 0.15^{\mathrm{b}}$ & $7.57 \pm 0.16^{\mathrm{b}}$ & $8.05 \pm 0.03^{\mathrm{b}}$ \\
& 2 & $6.13 \pm 0.14^{\mathrm{c}}$ & $7.24 \pm 0.08^{\mathrm{c}}$ & $8.10 \pm 0.17^{\mathrm{b}}$ \\
\hline \multirow{3}{*}{$\mathrm{SIJ}$ (pH 7.5) } & 3 & $6.10 \pm 0.14^{\mathrm{c}}$ & $7.18 \pm 0.02^{\mathrm{c}}$ & $7.25 \pm 0.04^{\mathrm{c}}$ \\
& 4 & $6.08 \pm 0.13^{\mathrm{c}}$ & $7.06 \pm 0.02^{\mathrm{cd}}$ & $7.12 \pm 0.05_{\mathrm{cd}}$ \\
& 5 & $5.97 \pm 0.06^{\mathrm{c}}$ & $6.96 \pm 0.10^{\mathrm{d}}$ & $7.02 \pm 0.07 \mathrm{~d}$ \\
\hline
\end{tabular}

a-dMeans \pm standard deviations followed by different superscript letters within the same column are significantly different at $\mathrm{p} \leq 0.05$ according to Tukey's test $(\mathrm{n}=3)$. 
Table 5. Survivability of BB-12 free cell and microencapsulated BB-12 with and without mannitol under sequential digestion.

\begin{tabular}{ccccc}
\hline $\begin{array}{l}\text { Sequential } \\
\text { incubation }\end{array}$ & Time (h) & Free cell & Encapsulated BB-12 & $\begin{array}{c}\text { Encapsulated BB-12 } \\
\text { with mannitol }\end{array}$ \\
\cline { 3 - 5 } & 0 & $100.00 \pm 0.00^{\mathrm{a}}$ & $100.00 \pm 0.00^{\mathrm{a}}$ & $100.00 \pm 0.00^{\mathrm{a}}$ \\
SGJ (pH 2.0) & 1 & $91.26 \pm 2.78^{\mathrm{b}}$ & $91.70 \pm 1.40^{\mathrm{b}}$ & $96.31 \pm 0.39^{\mathrm{b}}$ \\
& 2 & $73.95 \pm 1.69^{\mathrm{c}}$ & $87.33 \pm 0.85^{\mathrm{c}}$ & $97.28 \pm 1.39^{\mathrm{b}}$ \\
\hline \multirow{3}{*}{$\mathrm{SIJ}$ (pH 7.5) } & 3 & $73.57 \pm 1.86^{\mathrm{c}}$ & $86.53 \pm 0.34^{\mathrm{cd}}$ & $86.77 \pm 0.55^{\mathrm{c}}$ \\
& 4 & $73.29 \pm 0.85^{\mathrm{c}}$ & $85.08 \pm 0.36^{\mathrm{de}}$ & $85.13 \pm 0.38^{\mathrm{cd}}$ \\
& 5 & $71.99 \pm 1.50^{\mathrm{c}}$ & $83.47 \pm 0.38^{\mathrm{e}}$ & $83.64 \pm 0.27^{\mathrm{d}}$ \\
\hline
\end{tabular}

a-eMeans \pm standard deviations followed by different superscript letters within the same column are significantly different at $\mathrm{p} \leq 0.05$ according to Tukey's test ( $\mathrm{n}=3$ ).

\section{CONCLUSION}

In conclusion, encapsulated BB-12 coated with $0.4 \%(\mathrm{w} / \mathrm{v})$ chitosan and incorporated with $3 \%$ $(\mathrm{w} / \mathrm{v})$ mannitol showed higher microencapsulation efficiency $(89.15 \%)$ as compared to encapsulated BB-12 without mannitol. The encapsulated BB-12 with and without mannitol were spherical with a smooth surface, and the average bead diameter was ranged between 758-805 $\mu \mathrm{m}$. The encapsulated BB-12 with and without mannitol produced by coextrusion were able to preserve their viability above $10^{6} \mathrm{CFU} / \mathrm{mL}$ as compared to free BB-12 were after 5 hours of sequential simulated gastrointestinal digestion. This also shows that chitosan-coated alginate beads were able to protect the BB-12 from adverse conditions during digestive transit. The addition of mannitol enhanced the survivability of BB-12 during simulated gastric conditions due to its prebiotic effect.

\section{ACKNOWLEDGMENTS}

The project was supported by UCSI University Pioneer Scientist Incentive Fund (PSIF) grant (Proj-In-FAS-055).

\section{REFERENCES}

Bernucci, B., Loures, C., Lopes, S., Oliveira, M., Sabino, A., Vilela, J., Andrade, M., Lacerda, I., Nicoli, J., \& Oliveira, E. 2017.
Effect of microencapsulation conditions on the viability and functionality of Bifidobacterium longum $51 \mathrm{~A}$. LWT- Food Science and Technology 80(1): 341-347.

Chan, E., Lee, B., Ravindra, P., \& Poncelet, D. 2009. Prediction models for shape and size of calcium-alginate macrobeads produced through extrusion-dripping method. Journal of Colloid and Interface Science 338(1): 63-72.

Chávarri, M., Marañón, I., Ares, R., Ibáñez, F. C., Marzo, F. M, \& del Carmen Villarán, M. 2010. Microencapsulation of a probiotic and prebiotic in alginate-chitosan capsules improves survival in simulated gastrointestinal conditions. International Journal of Food Microbiology 142(1-2): 185-189.

Chew, S. C., Tan, C. P., Long, K., \& Nyam, K. L. 2015. In-vitro evaluation of kenaf seed oil in chitosan coated-high methoxyl pectin-alginate microcapsules. Industrial Crops and Products 76(1): 230-236.

Chia, P. X., Tan, L. J., Huang, C. M., Chan, E. W., \& Wong, S. Y. 2015. Hydrogel beads from sugar cane bagasse and palm kernel cake, and the viability of encapsulated Lactobacillus acidophilus. E-Polymers 15(6): 24-29.

Cook, M. T., Tzortzis, G., Charalampopoulos, D., \& Khutoryanskiy, V. V. 2011. Production and evaluation of dry alginate-chitosan microcapsules as an enteric delivery vehicle for probiotic bacteria. Biomarcomolecules 12(7): 28342840.

Das, A., Ray, S., Raychaudhuri, U., \& Chakraborty, R. 2014. Microencapsulation of probiotic bacteria and its potential application in food technology. International Journal of Agriculture, Environment and Biotechnology 6 (1): 63-69.

Dolçà, C., Ferrándiz, M., Capablanca, L., Franco, E., Mira, E., López, F., \& García, D. 2015. Microencapsulation of rosemary essential oil by co-extrusion/gelling using alginate as a wall material. Journal of Encapsulation and Adsorption Sciences 5 (3): 121-130.

Du, H, Liu, M., Yang, X., \& Zhai, G. 2015. The design of pHsensitive chitosan-based formulations for gastrointestinal delivery. Drug Discovery Today 20 (8): 1004-1011.

Etchepare, M. D., Raddatz, G. C., Flores, E. M. D. M., Zepka, L. Q., Lopes, E. J., Barin, J. S., Grosso, C. R. F., \& Menezes, C. R. D. 2016. Effect of resistant starch and chitosan on survival of Lactobacillus acidophilus microencapsulated with sodium alginate. LWT-Food Science and Technology 65: 511517.

Garrigues, C., Johansen, E., \& Pedersen, M. 2010. Complete genome sequence of Bifidobacterium animalis subsp. lactis BB12 , a widely consumed probiotic strain. Journal of Bacteriology 192(9): 2467-2468.

Haghshenas, B., Nami, Y., Haghshenas, M., Barzcgari, A., Sharifi, S., Radiah, D., Rosli, R., \& Abdullah, N. 2015. Effect of 
addition of inulin and fenugreek on the survival of microencapsulated Enterococcus durans 39C in alginatepsyllium polymeric blends in simulated digestive system and yogurt. Asian Journal of Pharmacentical Sciences 10(4): 350-361.

Jantarathin, S., Borompichaichartkul, C., \& Sanguandeekul, R. 2017. Microencapsulation of probiotic and prebiotic in alginate-chitosan capsules and its effect on viability under heat process in shrimp feeding. Materials Today: Proceedings 4(5): 6166-6172.

Jungersen, M., Wind, A., Johansen, E., Christensen, J., StuerLauridsen, B., \& Eskesen, D. 2014. The science behind the probiotic strain Bifidobacterium animalis subsp. lactis BB$12^{\circledR}$. Microorganisms 2(2): 92-110.

Kechagia, M., Basoulis, D., Konstantopoulou, S., Dimitriadi, D., Gyftopoulou, K., Skarmoutsou, N., \& Fakiri, E. M. 2013. Health benefits of probiotics: a review. International Scholarly Research Notices Nutrition 1(1): 1-7.

Koo, S. M., Cho, Y. H., Huh, C. S., Baek, Y. J., \& Park, J. 2001. Improvement of the stability of Lactobacillus case $i$ YIT 9018 by microencapsulation using alginate and chitosan. Journal of Microbiology and Biotechnology 11(3): 376-383.

Krasaekoopt, W., Bhandari, B., \& Deeth, H. 2003. Evaluation of encapsulation techniques of probiotics for yoghurt. International Dairy Journal 13(1): 3-13.

Krasaekoopt, W., Bhandari, B., \& Deeth, H. 2004. The influence of coating materials on some properties of alginate beads and survivability of microencapsulated probiotic bacteria. International Dairy Journal 14(8): 737-743.

Krasaekoopt, W. 2013. Microencapsulation of probiotics in hydrocolloid gel matrices: a review. Agro Food Industry $\mathrm{Hi}$ Tech 24(2): 76-83.

Krasaekoopt, W., \& Watcharapoka, S., 2014. Effect of addition of inulin and galactooligosaccharide on the survival of microencapsulated probiotic in alginate beads coated with chitosan in simulated digestive system, yogurt and fruit juice. LWT - Food Science and Technology 57(2): 761-766.

Lai, J. T., Lai, K. W., Zhu, L. Y., Nyam, K. L., \& Pui, L. P. 2020. Microencapsulation of Lactobacillus plantarum $299 \mathrm{v}$ and its storage in kuini juice. Malaysian Journal of Microbiology in press.

Martín, M., Lara-Villoslada, F., Ruiz, M., \& Morales, M. 2015. Microencapsulation of bacteria: a review of different technologies and their impact on the probiotic effects. Innovative Food Science and Emerging Technologies 27(1): $15-25$.

Mustafa, S., Chua, L., El-Enshasy, H., Majid, F., \& Malek, R. 2016. A review on fruit juice probiotication: pomegranate. Current Nutrition and Food Science 12(1): 4-11.

Ng, S. L., Lai, K. W., Nyam, K. L., \& Pui, L. P. 2019. Microencapsulation of Lactobacillus plantarum 299v incorporated with oligofructose in chitosan coated-alginate beads and its storage stability in ambarella juice. Malaysian Journal of Microbiology 15(5): 408-411.

Nualkaekul, S., \& Charalampopoulos, D. 2011. Survival of Lactobacillus plantarum in model solutions and fruit juices. International Journal of Food Microbiology 146(2): 111117.

Pandey, K. R., Naik, S. R., \& Vakil, B. V. 2015. Probiotics, prebiotics and synbiotics-a review. Journal of Food Science and Technology 52(12): 7577-7587.

Piazza, L., \& Roversi, T. 2011. Preliminary study on microbeads production by co-extrusion technology. Procedia Food Science 1(1): 1374-1380.

Ruiz, L., Margolles, A., \& Sánchez, B. 2013. Bile resistance mechanisms in Lactobacillus and Bifidobacterium. Frontiers in Microbiology 4:396.

Schwendicke, F., Dörfer, C., Kneist, S., Meyer-Lueckel, H., \& Paris, S. 2014. Cariogenic effects of probiotic Lactobacillus rhamnosus GG in a dental biofilm model. Caries Research 48(3): 186-192.

Shinde, T., Sun-Waterhouse, D., \& Brooks, J. 2013. Co-extrusion encapsulation of probiotic Lactobacillus acidophilus alone or together with apple skin polyphenols: an aqueous and value-added delivery system using alginate. Food and Bioprocess Technology 7(6): 1581-1596.

Shori, A. 2017. Microencapsulation improved probiotics survival during gastric transit. HAY ATI Journal of Biosciences 24(1): 15.

Siang, S. C, Wai, L. K., Lin, N. K., \& Phing, L. P. 2019. Effect of added prebiotic (isomalto-oligosaccharide) and coating of beads on the survival of microencapsulated Lactobacillus rhamnosus GG. Food Science and Technology Campinas 39(S2): 601-609.

Silva, M., Tulini, F., Ribas, M., Penning, M., Fávaro-Trindade, C., \& Poncelet, D. 2016. Microcapsules loaded with the probiotic Lactobacillus paracasei BGP-1 produced by coextrusion technology using alginate/shellac as wall material: characterization and evaluation of drying processes. Food Research International 89(1): 582-590.

Solanki, H., Pawar, D., Shah, D., Prajapati, V., Jani, G., Mulla, A., \& Thakar, P. 2013. Development of microencapsulation delivery system for long-term preservation of probiotics as biotherapeutics agent. BioMed Research International 1(1): 121.

Succi, M., Tremonte, P., Pannella, G., Tipaldi, L., Cozzolino, A., Romaniello, R., Sorrentino, E., \& Coppola, R. 2017. Precultivation with selected prebiotics enhances the survival and the stress response of Lactobacillus rbamnosus strains in simulated gastrointestinal transit. Frontiers in Microbiology 8(1): $1-11$

Trabelsi, I., Bejar, W., Ayadi, D., Chouayekh, H., Kammoun, R., Bejar, S., \& Ben Salah, R. 2013. Encapsulation in alginate and alginate coated-chitosan improved the survival of newly probiotic in oxgall and gastric juice. International Journal of Biological Macromolecules 61(1): 36-42.

Tripathi, M. K., \& Giri, S. K. 2014. Probiotic functional foods: Survival of probiotics during processing and storage. Journal of Functional Foods 9: 225-241.

Vernazza, C. L., Gibson, G. R., \& Rastall, R. A. 2006. Carbohydrate preference, acid tolerance and bile tolerance in five strains of Bifidobacterium. Journal of Applied Microbiology 100(4): 846-853.

Wei, Y., Huang, Y. H., Cheng, K. C., \& Song, Y. L. 2020. Investigation of the influences of processing conditions on the properties of spray dried chitosan-tripolyphosphate particles loaded with theophylline. Scientific Reports 10: 1155.

Yee, W. L., Yee, C. L., Lin, N. K., \& Phing, P. L. 2019. Microencapsulation of Lactobacillus acidophilus NCFM incorporated with mannitol and its storage stability in mulberry tea. Ciência e Agrotecnologia 43: 1-11.

Zanjani, M. A. K., Tarzi, B. G., Sharifan, A. \& Mohammadi, N. 2014. Microencapsulation of probiotics by calcium alginategelatinized starch with chitosan coating and evaluation of survival in simulated human gastro-intestinal condition. Iranian Journal of Pharmaceutical Research: IJPR 13(3): 843. 